\title{
Implementation of the Internet Course on Conductive Adhesives for Electronics Packaging
}

\author{
Johan Liu, Liqiang Cao, Xitao Wang \\ Division of Electronics Production, \\ School of Mechanical and Vehicular Engineering, \\ Chalmers University of Technology, Argongatan 30, SE-43153 Mölndal, Sweden \\ johan.liu@me.chalmers.se \\ James E. Morris \\ Department of Electrical and Computer Engineering, Portland State University, Fourth Avenue Building Suite 160, 1900 \\ SW $4^{\text {th }}$ Avenue, P.O.Box 751, Portland OR 97207-0751, U. S. A. \\ j.e.morris@ieee.org
}

\begin{abstract}
The authors have developed a course on electrically conductive cdhesives for Internet delivery from multiple sites. The paper lays out detailed lecture by lecture content, and details of the experimental sequences, which include both high end analytical techniques and experiments which would be adaptable to any basic undergraduate laboratory environment. Today the course is now installed in an internet server for easy access.

The course starts with a general introduction of conductive adhesive joining technology, followed a section on ICA part. The course ends with the ACA part of the conductive adhesive technology. Both audio and video techniques are used to facilitate the study.
\end{abstract}

\section{Introduction}

The development of the worldwide web has provided unprecedented opportunity and challenge to the educational community for the delivery of immediate distance instruction, (real-time if desired,) and the range of Internet courses continues to expand exponentially.

While the development of Internet-based courses is clearly intended to reach off-campus students, one of the advantages is the opportunity for collaboration and cooperation with other campuses and universities, which can benefit regular full-time students too ${ }^{[1,2]}$.

In addition to course delivery, the Internet offers new opportunities for faculty and institutional cooperation at both the national and international levels. In this model, material is made available on a cooperative basis amongst faculty on different campuses. Such material may be selected as modules from a complete course, or may exist as independent modules available for adoption into others' courses. This is the model which most directly addresses the need identified by university faculty in forum discussion at the $1^{\text {st }}$ International Academic Packaging Conference at Georgia Institute of Technology, Atlanta, March 18-20, 1998, for multidisciplinary assistance in developing packaging course materials outside their own academic disciplines.

There is a structured effort under way to provide such modules (funded jointly by IEEE/CPMT and NSF,) and a real likelihood of them becoming available on a broad basis. The material currently available includes modules or self-contained courses on electronics manufacturing ${ }^{[3]}$, thermal design ${ }^{[4,5]}$, and signal integrity ${ }^{[6,7]}$. This paper presents the final achievement and design of a web-based internet course on conductive adhesives. Part of the result has already been reported ${ }^{[8] \text {. }}$

\section{ECA for Electronics Packaging}

There are two primary categories of ECA:

- Isotropically Conductive Adhesive (ICA)

- Anisotropically Conductive Adhesive (ACA).

- ACAs are available as paste or film (ACF).

Both types conduct through metal filler particles in an adhesive polymer matrix.

ECAs have been used for electronics packaging applications for decades in hybrid, die-attach and display assembly. There has been growing interest from the electronics industry over the past decade in other kinds of electronics packaging applications. While toxicity issues and environmental incompatibility of the lead in tin-lead solders triggered that greater interest at the outset, it has been the other evident advantages continue to drive further research. ECAs can offer the following additional potential advantages:

- Fine-pitch capability, especially when using ACAs for flip-chip

- Elimination of underfilling with ACA bonding;

- Low temperature processing capability;

- Flexible, simple processing and hence low cost

Current ECA research activities look forward to both flip-chip and surface mount technology (SMT) applications.

\subsection{Isotropic Conductive Adhesives (ICAs)}

Ag is usually used as the filler material due to its high conductivity and simple processing for ICA applications. Polymer based metal plated spheres or nickel fillers are mainly used for ACA applications. Figure 1 shows the microstructure of an ICA joint for a flip chip component on an FR-4 substrate. The metallic filler content is high enough (between 25-30 volume percent) to cause direct metallic contact.

\subsection{Anisotropic Conductive Adhesives (ACAs)}

In an ACA joint, the filler particle is normally between 5-10 volume percent, and does not cause any direct metallic contact. It is only after pressurization during curing that the electrical conduction becomes possible in the pressurization direction as is illustrated in Figure 2. As there is no direct contact between the particles, ACA 
technology is very suitable for small pitch assembly, and has found applications in flip-chip technology.

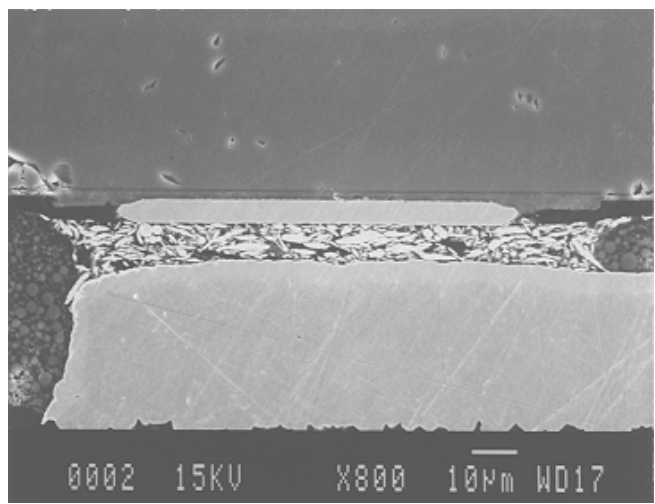

Figure 1. ICA flip- chip joint on an FR-4 substrate.

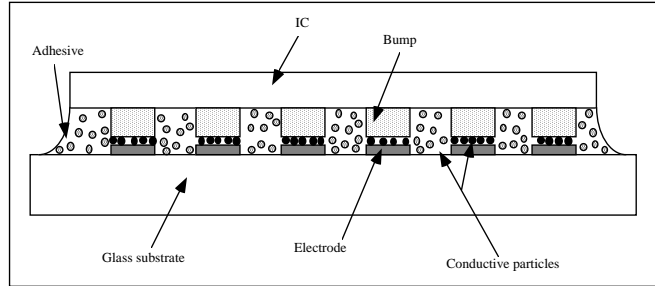

Figure 2. ACA flip-chip joint on a glass substrate.

\section{Implementation of the internet course}

The internet course is based on the existing short course taught jointly by the authors and the Chalmers University course for Ph.D. students, which deal with the fundamentals and applications of conductive adhesives in electronics packaging applications. The outline and introduction of these courses can be found in ${ }^{[9]}$.

The homepage of the internet course was written by hypertext makeup language (HTML). A web building software, such as FrontPage, was used. The whole course is separated as several interdependent modules of information. These modules are joined together through hyperlinks embedded into the HTML frame.

Figure 3 illustrates the main structure of the internet course. Welcome page (Figure 4) is the entrance of the web course. After that, it is the start page (Figure 5), where you can find the preface, objective, guidance of the course, and the sitemap of the whole website. In the guidance section, we give the users some instructions on how to use these web course materials. The 3rd stage is the index page. (Figure 6 ) There are 4 links in this page, which directed to the four parts of the course: Introduction, ECA, Isotropically Conductive Adhesive (ICA), and Anisotropically Conductive Adhesive (ACA). Next, you enter into the virtual classroom, your can start to learn with assistant of multimedia online lecture, lecture notes, lab tours, etc. The whole web pages are constructed and maintained by Chalmers University of Technology and Portland State University together. The general introduction of ECA is handled by both sides.
Chalmers and Portland State University take charge of the other two parts, ACA and ICA, respectively.

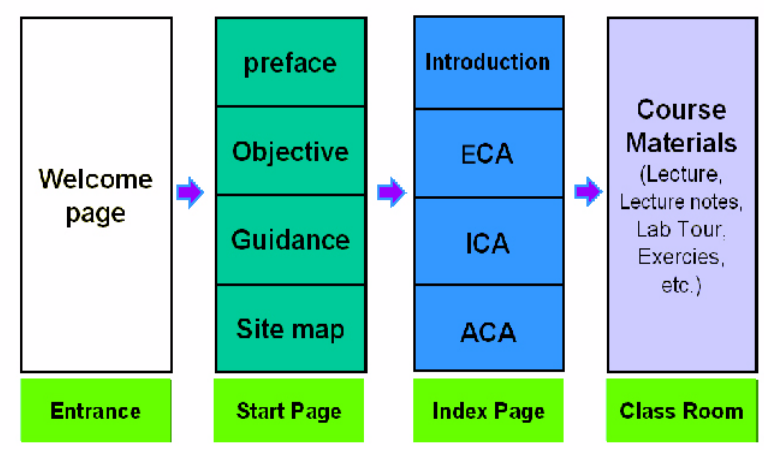

Figure 3. Main structure of the course

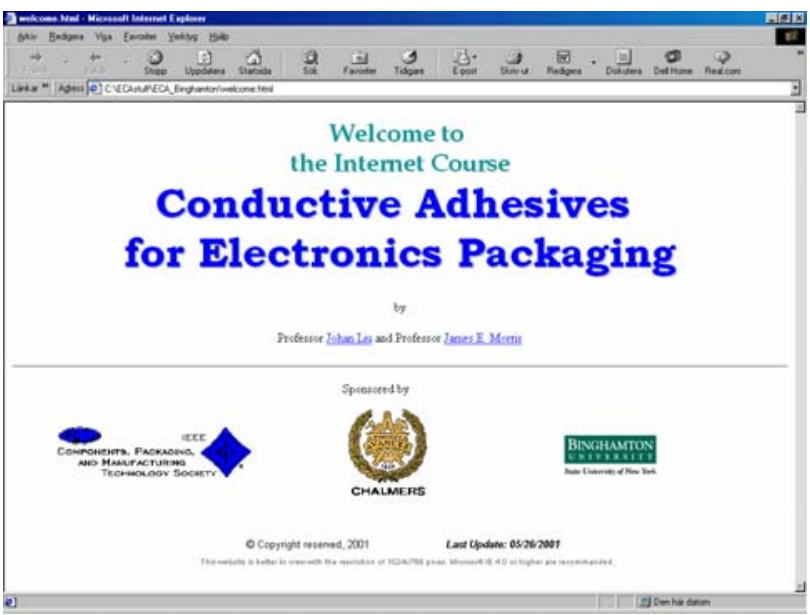

Figure 4. The welcome page of the course

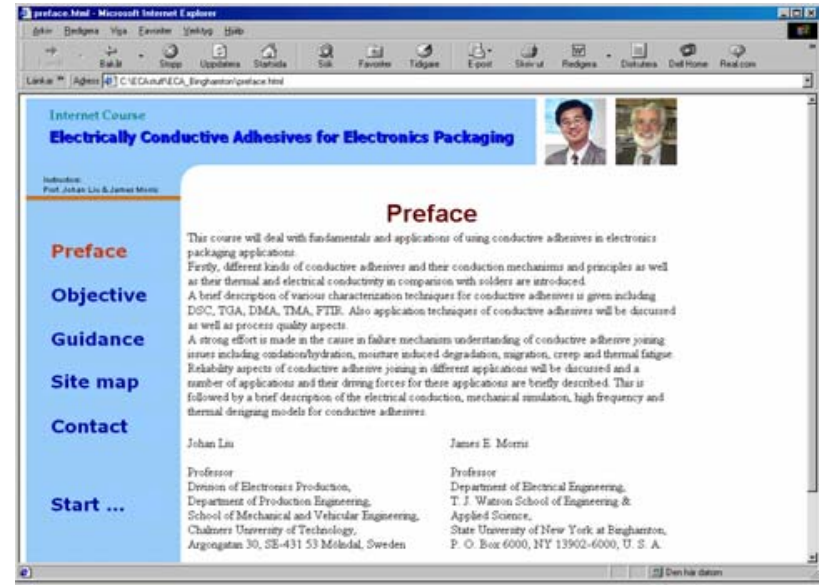

Figure 5. The start page 


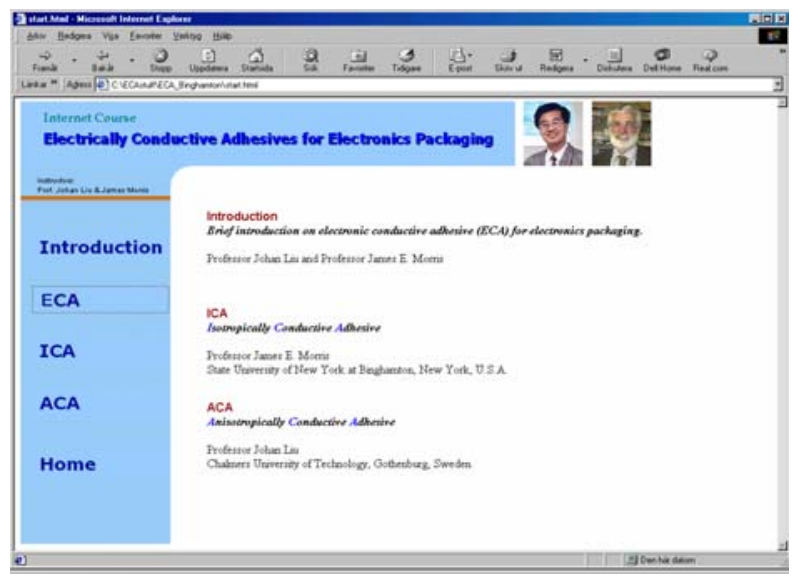

Figure 6. The index page

Contents of each part are similar. Figure 7 shows the items in ACA part. Nine sections exist in the ACA part:

- Content

- Multimedia lecture

- $\quad$ Lecture notes

- Text books

- Lab tour

- Glossary

- Exercises

- FAQ

- Links.

The content of ACA part is selected from the Chalmers Ph.D. student course mentioned before ${ }^{[9]}$. Each chapter and section in the content page is a hyperlink directed to the corresponding lecture. Section $2 \sim 5$ is the core of this part, details of them will be given later. In order to help the user to understand the materials well, glossary, FAQ (frequently asked question) and some useful electronics packaging links are included.

The structure of ICA part is similar with ACA part including nice sections. Figure 8 shows the item in ICA part.

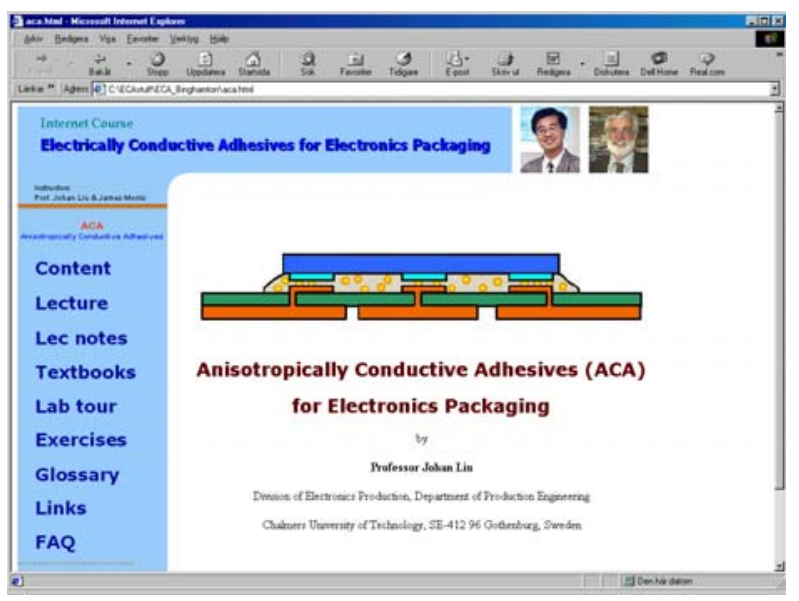

Figure 7. Interface of ACA part

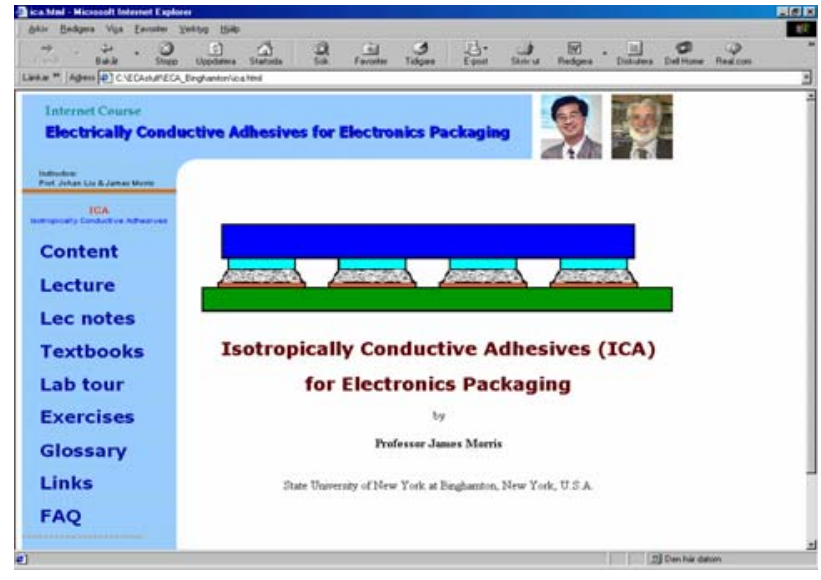

Figure 8 . Interface of ICA part

\subsection{Multimedia Lecture}

The multimedia lecture modules are created by using the Sync-O-Matic 2000 (the former name is Sync-OMatic 3000), developed by Dr. Charles Severance at Michigan State University ${ }^{[10]}$. Sync-O-Matic was developed for education purposes. It is currently in use in hundreds of locations around the world to produce webbased lectures. It combines audio, video, PowerPoint slides and the slide timing to provide high quality web lecture. The multimedia lectures are based the PowerPoint slides prepared for this course. As the first step, we only combined the audio explanation for these slides. The slideshow will play automatically with the voice from the instructor. The students can play the whole chapter, or a part starting from any slides. Students can select the slide from slides index or thumbnails. Figure 9 shows the interface of the multimedia lecture.

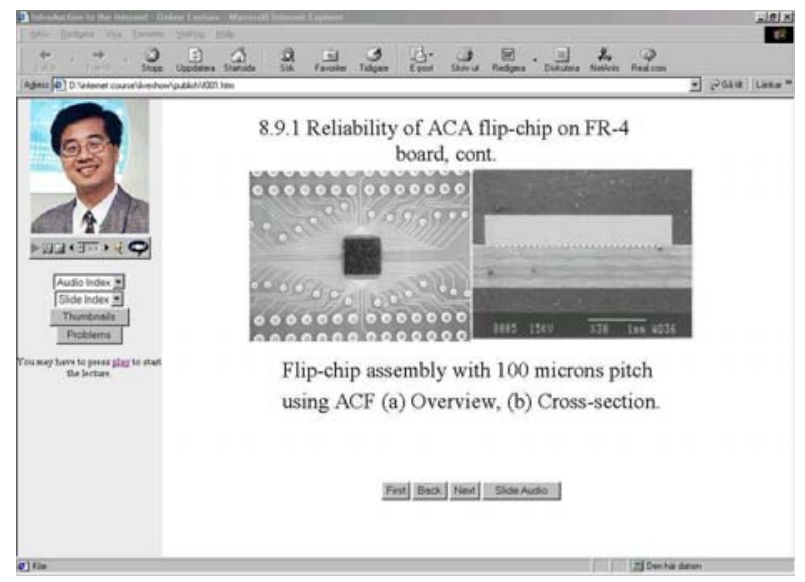

Figure 9. The multimedia lecture interface

\subsection{Lecture Notes}

Compare with the conventional campus lecture, the obvious advantage of the web course is you can play it as many times as you want. Although the web course can be played unlimited times, it is better to give the students the printable lecture notes. All the slides used in the multimedia lecture can be found in this section. Both PowerPoint and Acrobat format are given for different 
student's requirements. The lecture notes are separated as chapters in order to be downloaded. Other related materials, like discussion topics, comments from the teacher will be also included in the future.

\subsection{Text books}

The book "Conductive Adhesives for Electronics Packaging" edited by Johan Liu ${ }^{[11]}$ is selected as the principal text book for this course. The contents and introductions of this book also added on this page. A hyperlink to the publisher is available. Some selected chapter or sections might be scanned and added in this section under the permission of the author and publisher. Other reference books will be introduced by hyperlinks.

\subsection{Lab tour}

The lab tour is another important part of the course. It helps the students comprehend the knowledge they learned in the lecture. Finally, the lab tour will show the students the lab experimental process just as what they see in the real laboratory. In order to let the students be familiar with the lab, the instruments in the lab is introduced first. Therefore, two parts of lab tour were be provided here: the equipment and the process. In the instruments part, we put the picture, capability, specification, and the operation instruction of the instrument. The website of the "Electronics Packaging Virtual Laboratory" at Budapest University of Technology and Economics ${ }^{[12]}$ is a good example for us. The instruments introduced include:

- Plasma etching and cleaning equipment

- ACF Flip-Chip bonder

- Screenprinter

- Acustic Microscopy

- Dispenser

- Automatic pick and place machine

- Manual Pick \& Place equipment

- Hot air soldering machine

- Wave soldering equipment

- IR-soldering machine

- Vapour phase soldering machine

- Ultrasonic cleaner

- Pressure cooker

- $\quad$ Bond wire strength pull tester

- Shear tester

- Low cycle fatigue tester in elevated temperature and humidity

- Thermal bonder

- Ageing furnace

- Optic microscopic lab

- $\quad$ Laser-interferrometry for high resolution strain analysis in electronics packaging

- Multi-functional Mechanical Tester in humidity and elevated temperature environment

- Differential Scanning Calorimetry (DSC)

- Thermogravimetri Analyser (TGA)

- Dynamic Mechanical Analyser (DMA)

- Temperature measurement equipment for cooling of electronics

In the process part, following lab experiments will be illustrated.
- Designing conductive adhesive test vehicle

- Assembly of the conductive adhesive test vehicle

- Reliability test set up

- Data collection from the test vehicle

- Analytical instrument for inspecting the test vehicle

- Data analysis and conclusion of test

The process will be explained in detailed text with pictures as first stage. The web pages of the "The Virtual Packaging Laboratory" at Georgia Institute of Technology are nice design for this purpose ${ }^{[13]}$. In order to make the process more comprehensible, videos and/or animations to show the real lab operation should be added on the web in the future.

Some industry tour is also planed in this section.

\subsection{Video}

Concerning about the data transfer speed, we try to avoid using video on our web pages in the first stage. With the prevalence of the broadband internet, it will be possible to play the online video with certain quality. In the two most important sections of the course, multimedia lecture and lab tour, we expect the video can be added in next stage. The Sync-O-Matic can support the video as well, there is no software problem. However, we need a studio and related equipments to record the lecture and experiments. The video will consume huge storage space, we still need solve some problem on the web sever caused by the video.

\subsection{Interactive Exercises}

In order for the existing book to function effectively as a classroom text, it must be supplemented by a comprehensive set of quantitative problems and worked examples, with design integrated wherever possible. These materials will be placed on the web-site, along with a continuously updated listing of the literature readings mentioned above.( see Figure 10)

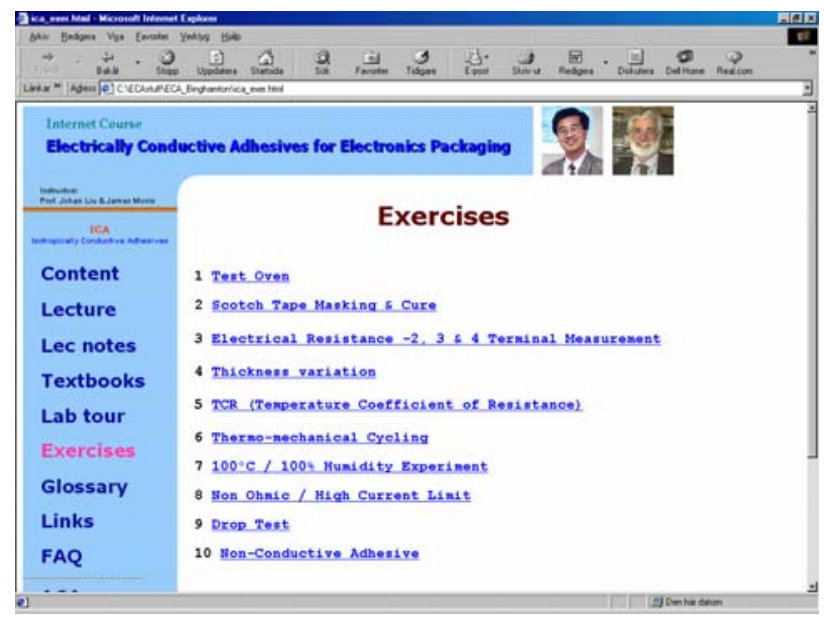

Figure 10. interface of exercise page

\section{Future plan}

The design and construction of the interactive web site is an ongoing process. To make the internet ECA course 
successful, there is still a lot of work to be done.

\subsection{Keep the course fresh}

The web pages should be updated continually. The project will also include the development of supplementary notes to continuously update the textbook material with the latest research data. Eventually this material will become incorporated into subsequent editions, but in the meantime the web-site/text combination will become a "living document" reference resource in the field.

\subsection{New Interactive exercise}

Some existed calculation programs can be revised and grafted on the web as interactive exercises. One candidate is the simulation program developed by L. Li and J. Morris at SUNY at Binghamton, We will investigate the possibility and try to make the interactive exercise available in the future.

\section{Conclusion}

An internet course on Conductive Adhesive for Electronics Packaging has developed with the cooperation of Chalmers University of Technology in Sweden and Portland State University in USA. The course is accessible soon through the internet. It provides the fundamentals and applications of conductive adhesives in electronics packaging applications. The students and engineers can improve their knowledge of ECA for electronics packaging by the multimedia lecture and lecture notes. It also provides a possibility for students to be familiar with the lab instruments and experiments.

\section{Acknowledgement}

This work is partially sponsored by the National Science Foundation, USA through Georgia Instiute of Technology and IEEE CPMT Society, USA.

\section{Reference}

1. Morris, J. E., and McCluskey, F. P. "A multidisciplinary sophomore course in electronic packaging" Proc. 48 ${ }^{\text {th }}$ IEEE Electronic Component \& Technology Conference (ECTC'98), Seattle, May 1998.

2. McCluskey, F. P., and Morris, J. E., "Multiuniversity, multidisciplinary distance learning experiment in electronics packaging education" Proc. $49^{\text {th }}$ IEEE Electronic Component \& Technology Conference (ECTC'99), San Diego, June 1999.

3. Light, D. L., Elshazly, D., and May, G., "Progress towards developing a web-based virtual packaging laboratory" Proc. $49^{\text {th }}$ IEEE Electronic Component \& Technology Conference (ECTC'99), San Diego, June 1999.

4. Yoshi, Y., Bar-Cohen, A., and Bhavnani, S., "Best practices in developing Internet based electronics packaging courseware: lessons from the international course on thermal design of electronic products"
Proc. $49^{\text {th }}$ IEEE Electronic Component \& Technology Conference (ECTC'99), San Diego, June 1999.

5 Yoshi, Y., Bar-Cohen, A., and Bhavnani, S., "Teaching thermal design of electronic systems on the Internet - the national course experience" presented at the $2^{\text {nd }}$ Academic Electronics Packaging Conference, Georgia Tech, March 1999.

6. Schutt-Aine, J. E., "Signal integrity education on the web” Proc. 49 ${ }^{\text {th }}$ IEEE Electronic Component \& Technology Conference (ECTC'99), San Diego, June 1999.

7. Schutt-Aine, J. E., "Web-based signal integrity education" presented at the $2^{\text {nd }}$ Academic Electronics Packaging Conference, Georgia Tech, March 1999.

8. Liu, J., Wang X.T. and Morris, J., "Development of an internet course on conductive adhesives", ECTC51th, May 30-June 2, 2001, Florida, USA, pp1270-1275.

9. Liu J. and Morris J. E., "An Internet Course on Conductive Adhesives for Electronics Packaging”, ECTC 50th , May 20-23, 2000, Las Vegas, USA, pp1016-1020.

10. Kim B.C. Severance C. "Multi-media enhancement of teaching electronic packaging education" Proceedings 49th IEEE Electronic Components and Technology Conference, San Diego, June 1999; p.904-906

11. Liu, Johan (editor), Conductive Adhesives for Electronics Packaging, Electrochemical Publications Ltd, (Port Erin, Isle of Ma n, UK, 1999.)

12. Péter Gordon, Péter Bojta, Lóránt Hertel, István Kállai, Imre Lepsényi, László Várnai, Zsolt Illyefalvi-Vitéz, "Progress in Electronics Packaging Virtual Laboratory Development”, Proceedings 50th IEEE Electronic Components and Technology Conference, Las Vegas, NV; May 2000; p.12931299.

13. D. Leigh Light and Gary S. May, "The Virtual Packaging Laboratory", Proceedings 50th IEEE Electronic Components and Technology Conference, Las Vegas, NV; May 2000; p.1300-1303. 